\title{
Selective Hydrogenation of 1,3-butadiene over Bimetallic Au-Ni/TiO Catalysts Prepared by Deposition-Precipitation with Urea
}

Antonio Aguilar-Tapia, ${ }^{1}$ Laurent Delannoy, ${ }^{2}$ Catherine Louis, ${ }^{2}$ Chang Wan $\mathrm{Han}^{3}$, Volkan Ortalan ${ }^{3}$, Rodolfo Zanella ${ }^{1 *}$

${ }^{1}$ Centro de Ciencias Aplicadas y Desarrollo Tecnológico, Universidad Nacional Autónoma de México, Circuito Exterior S/N, Ciudad Universitaria, A. P. 70-186, Delegación Coyoacán, C.P. 04510, México D. F. México

${ }^{2}$ Sorbonne Universités, UPMC Univ Paris 06, UMR CNRS 7197, Laboratoire de Réactivité de Surface, Case 178, 4 Place Jussieu, F-75252, Paris, France

3 School of Materials Engineering, Purdue University, West Lafayette, IN, USA

*Corresponding author: rodolfo.zanella@ccadet.unam.mx;

Tel. +52(55)56228601;

Keywords: Selective hydrogenation, Butadiene, Alkadiene, Gold, Nickel, Bimetallic catalysts, Au-Ni 


\section{Abstract}

Bimetallic Au-Ni supported on $\mathrm{TiO}_{2}$ were prepared using co-depositionprecipitation with urea and tested on the selective hydrogenation of 1,3 butadiene. The catalyst containing the lower amount of $\mathrm{Ni}$ (atomic Au:Ni 1:0.08) showed a satisfying compromise between activity provided by $\mathrm{Ni}$ and selectivity to butenes provided by $\mathrm{Au}$ for this selective hydrogenation reaction. Even though Au and Ni exhibit limited miscibility in the bulk, characterizations by TPR and UV-vis spectroscopy showed evidence of interaction between $\mathrm{Au}$ and $\mathrm{Ni}$ in nanoparticles. STEM-XEDS study confirmed the formation of bimetallic nanoparticles. 


\section{Introduction}

Selective hydrogenation of alkadiene and alkyne in alkene cuts is an important industrial process for the production of high purity alkene streams for further polymerization processes. Indeed, light alkenes produced by steam reforming contain a few percent of alkadienes and alkynes as impurities $[1,2]$, and the impurity level must be as low as $10 \mathrm{ppm}$ to avoid poisoning of the polymerization catalysts. Industrially, selective hydrogenation is catalyzed by Pd and Pd-Ag catalysts [3,4]. In the case of the $\mathrm{C} 4$ cut, the production of 1 -butene is important because it is used as co-monomer in polymer production. In recent works, Hugon et al. [5] studied the selective hydrogenation of 1,3-butadiene in the presence of a large excess of propene (propene/butadiene molar ratio of 100) to mimic the catalytic purification of a $\mathrm{C}_{4}$ cut over gold catalysts. They found that gold supported on different supports $\left(\mathrm{Al}_{2} \mathrm{O}_{3}, \mathrm{TiO}_{2}, \mathrm{ZrO}_{2}\right.$ and $\left.\mathrm{CeO}_{2}\right)$ and prepared by deposition-precipitation using urea exhibited better catalytic performance than gold catalysts prepared by impregnation in excess of solution and anionic adsorption. They also found that the catalytic behavior did not depend on the nature of the support. Under optimized reaction conditions, at $170{ }^{\circ} \mathrm{C}, 100 \%$ conversion of 1,3 -butadiene to butenes with 1 -butene as the main product was obtained. The incorporation of small amount of Pd promoted the activity remarkably, i.e. the temperature corresponding to total conversion $\left(\mathrm{T}_{100 \%}\right)$ of 1,3-butadiene decreased to $\sim 90{ }^{\circ} \mathrm{C}$ with less than $1 \%$ propene conversion using $\mathrm{Au}-\mathrm{Pd} / \mathrm{Al}_{2} \mathrm{O}_{3}$ with a $\mathrm{Au}: \mathrm{Pd}$ atomic ratio of 20 [6].

On the other hand, it is known that as palladium, nickel is a highly hydrogenating metal, but much less expensive, and it is used in reduction of 
aldehydes and ketones [7] or hydrogenation reactions [8]. Hence the goal of the present work was to study the effect of combining the highly hydrogenating nickel with gold, to explore the catalytic performances in the reaction of selective hydrogenation of 1,3-butadiene in the presence of an excess of propene.

\section{Experimental}

\subsection{Catalysts preparation}

Titania Evonik P25 was used as support $\left(45 \mathrm{~m}^{2} \mathrm{~g}^{-1}\right.$, nonporous, $70 \%$ anatase, $30 \%$ rutile, purity $>99.5 \%$ ). Commercial $\mathrm{HAuCl}_{4} \cdot 3 \mathrm{H}_{2} \mathrm{O}$ and $\mathrm{Ni}\left(\mathrm{NO}_{3}\right)_{2} \cdot 6 \mathrm{H}_{2} \mathrm{O}$, both from Aldrich, were used as gold and nickel precursors. Before preparation, $\mathrm{TiO}_{2}$ was dried in air at $100{ }^{\circ} \mathrm{C}$ for at least $24 \mathrm{~h}$ to dehydrate the support and favor further contact with the solution. The preparation of $1 \mathrm{wt} . \% \mathrm{Au} / \mathrm{TiO}_{2}$ and 0.28 wt. $\% \mathrm{Ni} / \mathrm{TiO}_{2}$ samples, i.e., the equivalent of 0.13 at\% for both elements, was performed by deposition-precipitation with urea (DPU) in the absence of light, following previously reported procedure [9-11]. Briefly, the gold precursor, $\mathrm{HAuCl}_{4}\left(4.2 \times 10^{-3} \mathrm{M}\right)$ or nickel precursor $\mathrm{Ni}\left(\mathrm{NO}_{3}\right)\left(4.2 \times 10^{-3} \mathrm{M}\right)$ and urea $(0.42$ M) were dissolved in $50 \mathrm{~mL}$ of distilled water. Then, $1 \mathrm{~g}$ of titania was added to this solution. Thereafter, the suspension temperature was increased to $80{ }^{\circ} \mathrm{C}$ thanks to hot water circulation in a double-wall reactor and kept constant under stirring for $16 \mathrm{~h}$.

After deposition-precipitation, the samples were washed with water and centrifuged four times, then dried under vacuum for $2 \mathrm{~h}$ at $80^{\circ} \mathrm{C}$. After drying, 
the samples were stored at room temperature in a desiccator under vacuum, away from light in order to prevent any alteration [10]. They are called asprepared samples in the following.

$\mathrm{Au}-\mathrm{Ni} / \mathrm{TiO}_{2}$ bimetallic catalysts were prepared by co-deposition-precipitation according to the method described above. The goal was to prepare samples with 1 wt.\% of $\mathrm{Au}$ and different $\mathrm{Ni}$ loadings, $0.14,0.06$ and 0.03 wt.\%, to achieve Au:Ni atomic ratios of 1:0.5, 1:0.2 and 1:0.1 respectively. Briefly, the gold precursor, $\mathrm{HAuCl}_{4}(0.0202 \mathrm{~g})$ and nickel precursor $\mathrm{Ni}\left(\mathrm{NO}_{3}\right)(0.0075,0.0035$ and $0.0015 \mathrm{~g}$ for the different loadings) were dissolved in $12 \mathrm{~mL}$ of distilled water, then urea $(0.302 \mathrm{~g})$ was added $\left(4.2 \times 10^{-3} \mathrm{M}_{\mathrm{Au}}, 2.2 \times 10^{-3}, 1 \times 10^{-3}\right.$ and $0.43 \times 10^{-3} \mathrm{M}_{\mathrm{Ni}}$ and $\left.0.42 \mathrm{M}_{\text {urea }}\right)$. Finally, $1 \mathrm{~g}$ of titania was added to this solution. Thereafter, the suspension temperature was increased to $80{ }^{\circ} \mathrm{C}$ thanks to hot water circulation in a double-wall reactor and kept constant under stirring for 16 h.

\subsection{Characterization techniques}

Chemical analysis of $\mathrm{Au}$ and $\mathrm{Ni}$ in the samples to determine the actual loadings was performed by X-ray fluorescence (XRF) using a spectrometer XEPOS HE (AMETEK). The Au and Ni weight loadings were expressed in grams of each metal per gram of sample.

After ex situ thermal treatment under the same conditions as for the 1,3butadiene hydrogenation reaction, i.e., under pure $\mathrm{H}_{2}\left(100 \mathrm{~mL} \mathrm{~min}^{-1}\right)$, from RT to $400{ }^{\circ} \mathrm{C}\left(2{ }^{\circ} \mathrm{C} \mathrm{min}^{-1}\right)$ then for $2 \mathrm{~h}$ at $400{ }^{\circ} \mathrm{C}$, the samples were examined by 
transmission electron microscopy in a Jeol-2010 FasTem analytical microscope equipped with a high-angle annular dark field (HAADF) detector. The average size of particles and the histograms of particles sizes were established from the measurement of 300 to 800 particles using a home-made software. The size limit for the detection of the metal particles on $\mathrm{TiO}_{2}$ was about $0.6 \mathrm{~nm}$. The volumetric average particle diameter $d_{v}$ was calculated with the formula: $d_{v}=\sum_{i=0}^{n}\left(d_{i}\right)^{3} / \sum_{i=0}^{n}\left(d_{i}\right)^{2}$ where $d_{i}$ is the particle diameter. The standard deviation was calculated with the formula: $\sigma=\left[\sum\left(d_{i}-d_{s}\right)^{2} / \sum n_{i}\right]^{1 / 2}$. To elucidate how $\mathrm{Au}$ and $\mathrm{Ni}$ interact with each other at the atomic scale, chemical composition and atomic structures of single nanoparticle in $\mathrm{Au}-\mathrm{Ni} / \mathrm{TiO}_{2}$ catalysts with 1:0.58 and 1:1 atomic ratios were characterized by a probe-aberration corrected scanning TEM (STEM) - JEOL ARM200CF equipped with an oxford XMAX 100TLE X-ray energy dispersive spectroscopy (XEDS) detector. An average atomic ratio of $\mathrm{Au}$ to $\mathrm{Ni}$ from a bulk $\mathrm{Au}-\mathrm{Ni} / \mathrm{TiO}_{2}$ was also obtained by XEDS at a low magnification ( 34 000) using an FEI Titan ETEM 80-300 equipped with an oxford XMAX 80T XEDS detector. XEDS quantification was performed by Oxford Aztec software. To interpret the contrast variations in HAADF-STEM images collected from Au-Ni/TiO 2 catalysts, a series of Zcontrast STEM image simulations were performed using the Monte Carlo electron trajectory simulation code - CASINO v3.2 [12].

Diffuse reflectance UV-Visible spectra of the as-prepared catalysts were obtained using a CARY5000 spectrophotometer equipped with a Praying Mantis and a high temperature reaction chamber (Harrick). The spectra were recorded from 300 to $800 \mathrm{~nm}$ during in situ thermal treatment under hydrogen. In each 
experiment, approximately $25 \mathrm{mg}$ of dried sample was packed in the sample holder and pretreated in situ under hydrogen flow $\left(30 \mathrm{~mL} \mathrm{~min}^{-1}\right.$ and $\left.2^{\circ} \mathrm{C} \mathrm{min}^{-1}\right)$ up to $400{ }^{\circ} \mathrm{C}$, followed by a 30 -min-plateau at the same temperature. $\mathrm{A}$ spectrum of Teflon (from Aldrich) was used as reference.

The hydrogen temperature programmed reduction $\left(\mathrm{H}_{2}-\mathrm{TPR}\right)$ study of the asprepared catalysts was performed in a Micromeritics-Autochem 2910 unit. 200 $\mathrm{mg}$ of sample were used and heated under a flow of $5 \% \mathrm{H}_{2} / \mathrm{Ar}$ gas mixture (25 $\mathrm{mL} \mathrm{min}^{-1}$ ) from room temperature to $800{ }^{\circ} \mathrm{C}$ with a heating rate of $7.5^{\circ} \mathrm{C} \mathrm{min}^{-1}$. $\mathrm{H}_{2} \mathrm{O}$ produced during the reduction process was trapped before the TCD detector.

\subsection{Catalytic activity}

The reaction of hydrogenation was carried out with $100 \mathrm{mg}$ of catalyst (sieve fraction, 125-200 $\mu \mathrm{m})$ in a plug flow microreactor in Pyrex $(4 \mathrm{~mm}$ of internal diameter). The as-prepared catalysts were activated in situ, under pure $\mathrm{H}_{2}(100$ $\left.\mathrm{mL} \mathrm{min}^{-1}\right)$, from $\mathrm{RT}$ to $400{ }^{\circ} \mathrm{C}\left(2{ }^{\circ} \mathrm{C} \mathrm{min}^{-1}\right)$, and kept $2 \mathrm{~h}$ at the final temperature. Then, the catalysts were cooled to room temperature under pure $\mathrm{H}_{2}$, and the reaction mixture consisting of $0.3 \%$ butadiene, $30 \%$ propene and $20 \%$ hydrogen in $\mathrm{He}(49.7 \%)$ was introduced at $\mathrm{RT}$ with a total flow rate of $50 \mathrm{~mL} \mathrm{~min}{ }^{-1}$, which corresponds to a space velocity of $30 \mathrm{~L} \mathrm{~g}^{-1} \mathrm{~h}^{-1}\left(\mathrm{GHSV}=20000 \mathrm{~h}^{-1}\right)$. The catalysts were heated under this gas mixture at a rate of $1^{\circ} \mathrm{C} \cdot \mathrm{min}^{-1}$, up to 300 ${ }^{\circ} \mathrm{C}$. Gas analysis at the outlet of the reactor was performed every 15 min, i.e., every $15^{\circ} \mathrm{C}$, between 30 and $300^{\circ} \mathrm{C}$. The analysis of the reaction products was 
performed by gas chromatography (Perichrom PR 2100, FID detector) using a 7.5 m column (1/8 in.) filled with sebaconitrile 25\% Chromosorb PAW 80/100 Mesh). Retention times and sensitivity factors for the reactants and products were calibrated using several gas mixtures. Software Winilab 4.0 was used for data acquisition and extraction of the concentrations of the different gases detected.

The selectivity of each product was calculated as:

$$
\frac{C_{P}}{C_{T}} \times 100
$$

Where $C_{P}$ represents the amount of the product whose selectivity is being calculated (\%) and $C_{T}$ the total amount of the products (butane + butenes) (\%).

The conversion of propene was calculated as:

$$
\frac{C_{\text {Propane outlet }}}{C_{\text {Propene inlet }}} \times 100
$$

Where $C_{\text {Propene inlet }}$ represents the initial amount propene (\%) and $C_{\text {Propane oulet }}$ the amount of propane produced (\%).

\section{Results}

\subsection{Elemental analysis and metal particle size}

The nominal metal loadings of the monometallic catalysts were $1 \mathrm{wt} . \%$ for $\mathrm{Au}$ and 0.28 wt. $\%$ for $\mathrm{Ni}$, which corresponds to 0.13 at $\%$ for both metals. Table 1 compares the nominal and the measured gold and nickel loadings in wt.\% in the samples after DPU as well as the $\mathrm{Au} / \mathrm{Ni}$ atomic ratio. As expected from former 
studies on gold catalysts $[9,11,13]$, the experimental gold loadings are very close to the theoretical value (1 wt.\%) whether the catalysts are mono or bimetallic. Moreover, almost all the nickel was deposited on $\mathrm{TiO}_{2}$ both in mono and bimetallic catalysts, which indicates that Ni can be efficiently deposited on $\mathrm{TiO}_{2}$ by the method of deposition-precipitation with urea. In the following, the bimetallic samples are identified as $\mathrm{Au}-\mathrm{Ni}$ followed by the measured $\mathrm{Au}: \mathrm{Ni}$ atomic ratio, e.g., Au-Ni 1:0.6, Au-Ni 1:0.2 and Au-Ni 1:0.08.

Figure 1 reports typical TEM-HAADF images showing metal particles of $\mathrm{Au} / \mathrm{TiO}_{2}, \mathrm{Ni} / \mathrm{TiO}_{2}$ and bimetallic $\mathrm{Au}-\mathrm{Ni} / \mathrm{TiO}_{2}$ samples after reduction at $400{ }^{\circ} \mathrm{C}$ and the corresponding histograms of particle sizes. Table 1 that also reports the corresponding average metal particle sizes, shows that the particles in the reduced bimetallic samples (2.2 to $2.7 \mathrm{~nm}$ ) have average size close to those in $\mathrm{Au} / \mathrm{TiO}_{2}(2.7 \mathrm{~nm})$ and smaller than in $\mathrm{Ni} / \mathrm{TiO}_{2}(4.2 \mathrm{~nm})$ samples; moreover, the average size seems to decrease as the loading of Ni decreases.

\subsection{Catalytic results in selective hydrogenation of 1,3-butadiene}

Figure 2 reports the evolution of the concentrations of butadiene and the different products, butenes and alkanes (butane and propane), as a function of the reaction temperature over monometallic $\mathrm{Au} / \mathrm{TiO}_{2}, \mathrm{Ni} / \mathrm{TiO}_{2}$ and three bimetallic $\mathrm{Au}-\mathrm{Ni} / \mathrm{TiO}_{2}$ catalysts after activation under $\mathrm{H}_{2}$ at $400{ }^{\circ} \mathrm{C}$. Table 2 gathers the conversion of propene and the selectivities to butenes at the temperature corresponding to $100 \%$ butadiene conversion $\left(T_{100 \%}\right)$.

Figure 2A shows that over $\mathrm{Au} / \mathrm{TiO}_{2}$, the whole butadiene has been converted into butenes at $\mathrm{T}_{100 \%}$ of $225{ }^{\circ} \mathrm{C}$ with $100 \%$ selectivity to butenes (no formation of 
butane), and with a very low conversion of propene into propane $(0.2 \%)$ that remained low even at $300{ }^{\circ} \mathrm{C}(0.4 \%)$. Regarding the selectivities to butenes, 1 butene is the main butene produced on gold catalysts, and among the two 2butene isomers, the cis-2-butene is the main product; this is peculiar to the group IB metal catalysts as the trans-2-butene is thermodynamically more stable than the cis-one and is the predominant 2-butene for conventional hydrogenation catalysts based on $\mathrm{Pd}$ or $\mathrm{Ni}$ [14-16]. The gold catalytic behavior is in agreement with a former study performed with the same type of sample [5]. Monometallic $\mathrm{Ni} / \mathrm{TiO}_{2}$ is much more active and highly hydrogenating (Figure 2B) as $100 \%$ conversion of butadiene has been already reached at $30{ }^{\circ} \mathrm{C}$ with a selectivity to butenes (with trans-2 butene as the main isomer) of only $52 \%$ and a conversion of propene into propane of $17 \%$ (Table 2).

The catalytic behavior of the three bimetallic $\mathrm{Au}-\mathrm{Ni} / \mathrm{TiO}_{2}$ catalysts are reported into Figure 2D-F. As expected, the bimetallic catalyst with the highest amount of $\mathrm{Ni}(\mathrm{Au}-\mathrm{Ni}$ 1:0.6), i.e., with the same Ni loading than in the monometallic catalyst, was the most active bimetallic one (Table 2), and reached $100 \%$ conversion of butadiene at $45{ }^{\circ} \mathrm{C}$ but with 10 times less alkanes formed than with the monometallic Ni sample at $30^{\circ} \mathrm{C}$, i.e., with a selectivity to butenes of $94 \%$ and conversion of propene into propane around 1\% (Table 2). To ensure that the behavior of the bimetallic catalyst was due to the presence of bimetallic particles, a mechanical mixture of monometallic $\mathrm{Au} / \mathrm{TiO}_{2}(1 \mathrm{wt} . \%)$ and $\mathrm{Ni} / \mathrm{TiO}_{2}$ (0.2 wt.\%) was prepared in order to obtain an atomic Au:Ni ratio of 1:0.6. Figure $2 \mathrm{C}$ shows that the catalytic behavior of the mechanical mixture is quite similar to 
the one of monometallic $\mathrm{Ni} / \mathrm{TiO}_{2}$ (Figure $2 \mathrm{~B}$ ). This result indicates that an interaction between $\mathrm{Au}$ and $\mathrm{Ni}$ exists in the bimetallic $\mathrm{Au}-\mathrm{Ni} / \mathrm{TiO}_{2}$ catalysts.

The Au-Ni 1:0.2 catalyst in Figure 2E reached 100\% conversion of butadiene at $90{ }^{\circ} \mathrm{C}$ with a lower formation of alkanes (selectivity to butenes of $99 \%$ and $0.8 \%$ conversion of propene). The Au-Ni 1:0.08 sample (Figure 2F) was the least active one, and reached $100 \%$ of conversion of butadiene at $120{ }^{\circ} \mathrm{C}$ but with almost $100 \%$ selectivity to butenes and a very low conversion of propene $(0.3 \%)$. This sample is therefore much more active than $\mathrm{Au} / \mathrm{TiO}_{2}$, and almost as selective.

Interestingly, trans-2-butene is the major butene isomer for all the bimetallic catalysts, which reflect a catalytic behavior closer to $\mathrm{Ni}$ than to $\mathrm{Au}$, as discussed previously, even at low $\mathrm{Ni}$ content. It may indicate that the addition of $\mathrm{Ni}$ to $\mathrm{Au}$ catalysts not only enhances the hydrogenation properties but also favors the isomerization of 1-butene and cis-2-butene into trans-2-butene.

Before discussing more deeply the catalytic results, additional characterization results of the samples are presented in the following sections.

\subsection{TPR characterization}

The reducibility of the as-prepared samples was studied by TPR up to $800{ }^{\circ} \mathrm{C}$. The reduction profile of $\mathrm{Au} / \mathrm{TiO}_{2}$ (Figure 3A) appeared as a single peak with a maximum at $130{ }^{\circ} \mathrm{C}$, with a surface area of 9.45 a.u.;. this reduction peak has been assigned to the reduction of the $\mathrm{Au}^{\mathrm{III}}$ species deposited during the DP urea process [17]. There was also a single peak in the reduction profile of the $\mathrm{Ni} / \mathrm{TiO}_{2}$ sample (Figure 3B) between 200 and $400{ }^{\circ} \mathrm{C}$ with a maximum at $290{ }^{\circ} \mathrm{C}$ 
and a surface area of 8.5 a.u., which was associated to the reduction of $\mathrm{Ni}^{2+}$ to $\mathrm{Ni}^{0}[18,19]$. The TPR profile of Au-Ni/TiO 2 1:0.6 (Figure 3C) showed a peak with a shoulder at intermediate temperatures between those of reduction of the monometallic catalysts. From the decomposition of the TPR signal, one can tentatively propose that the reduction of gold occurred now at $135^{\circ} \mathrm{C}$ (surface area $=8.3$ a.u.) with a shoulder at $150^{\circ} \mathrm{C}$ (surface area $=4.4$ a.u.) that could be attributed to the reduction of nickel, which is roughly consistent with the fact that the bimetallic sample containing half the amount of $\mathrm{Ni}$ than the monometallic $\mathrm{Ni} / \mathrm{TiO}_{2}$. The reduction peak at higher temperature, between 440 and $690{ }^{\circ} \mathrm{C}$ could be related to the reduction of $\mathrm{Ti}^{4+}$ to $\mathrm{Ti}^{3+}$ assisted by the bimetallic particles formed at lower temperature [20].

An important point is that after TPR, the $\mathrm{Ni} / \mathrm{TiO}_{2}$ and $\mathrm{Au}-\mathrm{Ni} / \mathrm{TiO}_{2} 1: 0.6$ samples were exposed to ambient air for one week and submitted to a second TPR so as to detect the possible reoxidation of nickel. A very weak hydrogen consumption peak was observed between 80 and $125^{\circ} \mathrm{C}$ for the $\mathrm{Ni} / \mathrm{TiO}_{2}$ sample (Figure 3D), indicating surface reoxidation of the nickel particles during air contact. For the bimetallic Au-Ni sample, no hydrogen consumption was observed (Figure 3E). This may indicate that the presence of Au prevents or limits nickel reoxidation.

\subsection{UV-Visible characterization}

The UV-Visible spectra of the as-prepared $\mathrm{Au} / \mathrm{TiO}_{2}, \mathrm{Ni} / \mathrm{TiO}_{2}$, and $\mathrm{Au}-\mathrm{Ni} / \mathrm{TiO}_{2}$ 1:0.6 samples were recorded during in situ reduction under hydrogen at increasing temperature from RT to $400{ }^{\circ} \mathrm{C}$ (Figure 4). The monometallic Au 
sample (Figure 4A) developed a broad band between 400 and $800 \mathrm{~nm}$ with a maximum at $\sim 540 \mathrm{~nm}$ that increased in intensity as the reduction temperature increased, especially in the $135-170{ }^{\circ} \mathrm{C}$ range. This band was due to the surface plasmon resonance (SPR) of metallic gold nanoparticles [21-23], and attests for the reduction of the gold precursor. On the same time, the color of the sample changed from yellow at $\mathrm{RT}$ to violet at $135{ }^{\circ} \mathrm{C}$ due to the reduction of gold. In the case of the monometallic $\mathrm{Ni} / \mathrm{TiO}_{2}$ sample (Figure $4 \mathrm{~B}$ ), the absorbance in the visible region increased as temperature increased with a slight change of color, from initially light green to light gray at the end of the experiment, which could explain the overall increase of the absorbance.

For the bimetallic Au-Ni/TiO $1: 0.6$ sample (Figure 4C), a weak plasmon band related to $\mathrm{Au}^{0}$ was visible with a maximum at $\sim 530 \mathrm{~nm}$ and its intensity increased with temperature while the color of the sample changed from light yellow at $\mathrm{RT}$ to violet above $135^{\circ} \mathrm{C}$ indicating the reduction of gold. Since the metal particles in $\mathrm{Au} / \mathrm{TiO}_{2}$ and $\mathrm{Au}-\mathrm{Ni} / \mathrm{TiO}_{2}$ 1:0.6 samples have the same average size (Table 1), the strong attenuation of the plasmon band intensity of the $\mathrm{Au}-\mathrm{Ni} / \mathrm{TiO}_{2}$ sample (Figure $4 \mathrm{C}$ ), compared to that of the Au sample (Figure $4 \mathrm{~A})$, could be due to the presence of $\mathrm{Ni}$ and to its interaction with gold in the particles.

\subsection{Chemical composition of the metal particles in $\mathrm{Au}-\mathrm{Ni} / \mathrm{TiO}_{2}$ samples by electron microscopy}

Chemical compositional quantification of single nanoparticle was first performed with $\mathrm{Au}-\mathrm{Ni} / \mathrm{TiO}_{2}$ 1:0.6, by aberration-corrected STEM-XEDS. A total of 31 
particles randomly chosen were investigated (Table 3). Nine of them contained only monometallic gold, no monometallic nickel particles were found. The other particles contain both $\mathrm{Au}$ and $\mathrm{Ni}$, and are in the form of gold-rich bimetallic nanoparticles with compositions that depend upon the size of the nanoparticles (Table 3). The particles smaller than $4 \mathrm{~nm}$ contained a noticeable amount of $\mathrm{Ni}$ whereas particles larger than $4 \mathrm{~nm}$ were mostly $\mathrm{Au}$; this may indicate that for two non-miscible metals like $\mathrm{Au}$ and $\mathrm{Ni}$, the formation of bimetallics is favored in smaller particles, a similar effect has been observed in the limited miscibility system Au-Pt by Xiao et al. [24], they reported that on a nanoscale, besides structural effect and alloy composition, the particle size has a great influence on the heat of formation of the Au-Pt alloy nanoparticles. For small size alloy particles, the heat of formation of alloy nanoparticles is negative. In Z-contrast STEM imaging mode, the intensity contributed by an atom is approximately proportional to $Z^{2}$ (where $Z$ is the atomic number), with intensity being greater for heavier atoms $[25,26]$. HAADF-STEM is therefore an excellent method for determining the structure of the bimetallic particles. A representative nanoparticle of $1.5 \mathrm{~nm}$ size in $\mathrm{Au}-\mathrm{Ni} / \mathrm{TiO}_{2}$ 1:0.6 is shown in Figure 5A. No contrast was observed, which may indicate that the particle was alloy-type. As mentioned above, the Ni contents in the bimetallic nanoparticles (Table 3) are much lower than the bulk value determined by the XRF. In order to verify the total $\mathrm{Ni}$ loading of the sample, TEM-XEDS spectra were also collected from the bulk of the Au-Ni 1:0.6 catalyst over a total of 20 different large areas including support and metal particles. As exemplified in Figures 5B and 5C, the average atomic ratio of $\mathrm{Au}$ to $\mathrm{Ni}$ was found to be 1:0.41 \pm 0.20 , which is rather consistent with the initial loading 1:0.6. Therefore, it can be inferred that the rest of the $\mathrm{Ni}$ 
not present in the bimetallic Au-Ni nanoparticles forms isolated Ni nanoparticles on the titania support, i.e. apart from the bimetallic particles. However, due to the inherent nature of the Z-contrast STEM imaging, the signal coming from the isolated $\mathrm{Ni}$ nanoparticles in the presence of $\mathrm{Au}$ is extremely weak causing direct observation of the isolated $\mathrm{Ni}$ nanoparticles extremely challenging. Image simulations were performed in order to assess the feasibility of imaging isolated Ni nanoparticles in the presence of Au. HAADF-STEM simulated images for 1 $\mathrm{nm}$ and $3 \mathrm{~nm}$ Ni particles along with a $3 \mathrm{~nm}$ Au particle (Figure $6 \mathrm{~A}$ ) verify that $\mathrm{Ni}$ nanoparticles are not clearly visible in the presence of $A u$ nanoparticles on $\mathrm{TiO}_{2}$, and their visualization together with the high-Z elements (such as $\mathrm{Au}$ nanoparticles) through HAADF-STEM imaging is extremely challenging, especially for the Ni particles smaller than $1 \mathrm{~nm}$. Hence, the observation of $\mathrm{Ni}$ nanoparticles requires spectroscopic imaging, such as XEDS. To clearly visualize the interaction between $\mathrm{Au}$ and $\mathrm{Ni}$, a catalyst with higher $\mathrm{Ni}$ loading corresponding to an $\mathrm{Au}: \mathrm{Ni}$ atomic ratio of 1:1 was also synthesized. As can be seen in Figure 6B, the Ni nanoparticles, which were invisible in the Z-contrast image (leftmost panel in Figure 5B), are clearly shown in Ni-K line XEDS background subtracted map (rightmost panel in Figure 6B), verifying the presence of the isolated $\mathrm{Ni}$ nanoparticles in the $\mathrm{Au}-\mathrm{Ni} / \mathrm{TiO}_{2}$ 1:1 sample. However, the possibility that these particles contain a low proportion of gold atoms not detectable by mapping cannot be excluded. One can add that these particles are very small, around $1 \mathrm{~nm}$ and even smaller. To summarize the electron microscopy results, the Au-Ni sample 1:0.6 contains bimetallic particles of $2.7 \mathrm{~nm}$ in average, enriched in gold and probably tiny monometallic $\mathrm{Ni}$ particles or gold poor particles smaller than $1 \mathrm{~nm}$ as in the sample 1:1. One can 
assume that the samples with lower amount of $\mathrm{Ni}$ also contain the same type of particles. STEM-XEDS and EELS analyses of single nanoparticles in the Au$\mathrm{Ni} / \mathrm{TiO}_{2}$ 1:0.08 were also performed, but no evidence of existence of bimetallic nanoparticles was obtained; this does not mean that bimetallic nanoparticles are not formed because the sensibility of the STEM-XEDS technique is at the best 0.5 at.\%.

\section{Discussion}

The characterization study presented above shows evidence of the existence of interaction between $\mathrm{Au}$ and $\mathrm{Ni}$ in the bimetallic samples, in spite of the poor miscibility of gold and nickel: (i) UV-Visible spectroscopy shows that the intensity of the gold plasmon band of the reduced Au-Ni (1:0.6) sample (Figure $4 \mathrm{C}$ ) is much lower than the one of the monometallic Au sample (Figure 4A); (ii) $\mathrm{Ni}$ is reduced at lower temperature in the presence of gold (the shoulder visible at $150^{\circ} \mathrm{C}$, Figure $3 \mathrm{C}$ ) than in monometallic $\mathrm{Ni} / \mathrm{TiO}_{2}$ (Figure $3 \mathrm{~B}$ ). This may indicate that the reduction of $\mathrm{Ni}^{2+}$ is assisted by metallic $\mathrm{Au}$ formed at slightly lower temperature $\left(135^{\circ} \mathrm{C}\right.$, Figure $\left.3 \mathrm{C}\right)$; (iii) the comparison of the TPR profiles of the $\mathrm{Au}-\mathrm{Ni} / \mathrm{TiO}_{2}$ and $\mathrm{Au} / \mathrm{TiO}_{2}$ samples after first TPR then exposure to air reveals an inhibition of the reoxidation of $\mathrm{Ni}^{0}$ species in the bimetallic sample (Figure 3E to be compared to Figure 3D).

The co-existence of $\mathrm{Au}$ and $\mathrm{Ni}$ in single nanoparticles attested by aberrationcorrected STEM-XEDS analysis (Figure 5B and C and Table 3 ) is a direct proof of the bimetallic character of the particles although those, which were imaged, 
were enriched in gold. Moreover, the fact that the Au-Ni (1:1) sample clearly contains tiny $\mathrm{Ni}$ particles $(\leq 1 \mathrm{~nm})$, and that the particles in the $\mathrm{Au}-\mathrm{Ni}(1: 0.6)$ sample exhibit an $\mathrm{Au} / \mathrm{Ni}$ ratio much higher than the nominal one (Table 3 ) is also an indication that this sample also contains tiny Ni particles. It is probable that the samples containing less $\mathrm{Ni}$ contained a lower number of these $\mathrm{Ni}$ monometallic particles.

One can note that the lower reduction temperature of $\mathrm{Ni}$ in $\mathrm{Au}-\mathrm{Ni}$ (Figure 3C) than in Ni samples (Figure 3B) could explain the smaller particle size obtained in the bimetallic Au-Ni sample by comparison with monometallic Ni. Moreover, if it is assumed that $\mathrm{Au}$ and $\mathrm{Ni}$ do not interact with each other, Ni nanoparticles of about $4 \mathrm{~nm}$ should be observed in the bimetallic samples (Table 1). However $\mathrm{Ni}$ nanoparticles having this size were not observed in the bimetallic samples, which could indicate that $\mathrm{Au}$ has an effect of reducing the size of $\mathrm{Ni}$ nanoparticles below its visibility limit. This result could suggest the formation of Au-Ni bimetallic nanoparticles.

The catalytic results in Figure $2 \mathrm{~A}$ and $2 \mathrm{~B}$ confirm that gold is much less active than nickel catalysts, but is much more selective to semi-hydrogenation than nickel, which is a very hydrogenating and poorly selective catalyst. It has been reported $[5,27]$ that the reason for the high selectivity of monometallic $\mathrm{Au}$ catalysts is that gold binds more weakly alkenes than butadiene, and that the two reactions of hydrogenation of butadiene and propene operate in two different ranges of temperature, independent from each other i.e., at higher $\mathrm{T}$ for propene than for butadiene. 
The results in Figure 2D-F show that the addition of various amounts of $\mathrm{Ni}$ to $\mathrm{Au}$ modifies their respective catalytic properties. The bimetallic catalysts show intermediate activities, but the production of alkanes at $\mathrm{T}_{100 \%}$ is much lower $(0.3-1 \%$ of conversion of propene, Table 2$)$ than for monometallic $\mathrm{Ni}(17 \%$ of conversion of propene), i.e., the selectivity to butenes is much higher. A comparison among the bimetallic catalysts also shows that, when the Ni content decreases, $T_{100 \%}$ increases, and the selectivity to butenes increases. Hence, the bimetallic Au-Ni 1:0.08 sample shows the highest selectivity to butenes, close to that of gold (Table 2), although $\mathrm{T}_{100 \%}$ is $\sim 100^{\circ} \mathrm{C}$ lower, and the catalyst is much more active. To the light of these results, one can assess that it is possible to improve the catalytic activity of gold and on the same time maintain the high selectivity to butenes at $\mathrm{T}_{100 \%}$ by tuning the proportion of $\mathrm{Au}$ and $\mathrm{Ni}$ in the bimetallic catalysts. A parallel can be established with one of our earlier studies on bimetallic Au-Pd catalysts supported on $\mathrm{Al}_{2} \mathrm{O}_{3}$ in the same reaction [6]. It was observed that the addition of low amounts of Pd in Au samples (at./at. $\mathrm{Au} / \mathrm{Pd}=20)$ also led to an increase of the catalytic activity while the high selectivity to butenes was maintained. This was proposed to result from the enhancement of chemisorbed $\mathrm{H}_{2}$ uptake due to the high $\mathrm{H}_{2}$ dissociation capacity of $\mathrm{Pd}$ sites, which is the rate limiting step of the reaction over gold catalysts [27]. As $\mathrm{Pd}, \mathrm{Ni}$ has a high $\mathrm{H}_{2}$ dissociation capacity that explains the catalytic results observed in Figure 2B. Ni has the advantage over Pd that it is a more abundant and cheaper base metal.

In addition, it is interesting to note that in spite of the fact that monometallic $\mathrm{Ni}$ and bimetallic Au-Ni (1:0.6) contain almost the same amount of nickel (0.24 and 
0.2 wt.\%, respectively (Table 1), and that Au-Ni (1:0.6) sample certainly contains very small Ni particles of less than $1 \mathrm{~nm}$, the Au-Ni catalyst is less active than the $\mathrm{Ni}$ one (Figure $2 \mathrm{~B}$ ), and than the mechanical mixture of $\mathrm{Au} / \mathrm{TiO}_{2}$ and $\mathrm{Ni} / \mathrm{TiO}_{2}$ (Figure $2 \mathrm{C}$ ). Above all, the selectivity to butenes is much higher: $94 \%$ against $53 \%$ and $\sim 10$ times less propane produced than for the monometallic Ni sample at $30^{\circ} \mathrm{C}$ (Table 2). As this stage, it is difficult to conclude on the extent of the contribution of these very small Ni particles to the catalytic properties. One may wonder (i) whether they participate to the catalytic activity, but are more selective than the larger ones of the $\mathrm{Ni}$ catalyst, in a similar way as $\mathrm{Pd}$ atomically dispersed on a substrate becomes very selective to semi-hydrogenation $[28,29]$ or (ii) whether they are not active at all because of the absence of the minimum number of $\mathrm{Ni}$ surface atoms (Ni ensemble sites) required to adsorb molecules like propene or butadiene or (iii) whether they contain a low proportion of gold not detectable by STEM-XEDX for sensivity reasons (Figure 6B) but high enough to modify the catalytic properties as observed for instance in the Au-Ni 1:0.08 sample or (iv) whether strong interaction with the titania support modifies their catalytic properties. One could also consider the possibility of formation of nickel titanate; however, this hypothesis can be discarded because calcination at high temperature (above $\left.700^{\circ} \mathrm{C}\right)$ is necessary to form this species [30-32].

\section{Conclusion}

In conclusion, the present work shows that the addition of a low amount of $\mathrm{Ni}$ to supported Au catalysts promotes the activity of gold catalysts in the reaction of selective hydrogenation of 1,3-butadiene, keeping a high selectivity to butenes, 
i.e. avoiding the complete hydrogenation of alkenes. Co-deposition-precipitation of $\mathrm{Au}$ and $\mathrm{Ni}$ with urea is an appropriate preparation method to deposit both metals, and prepare bimetallic nanoparticles, as shown by the different characterization techniques, in spite of the fact that $\mathrm{Au}$ and $\mathrm{Ni}$ are poorly miscible. However, the largest particles observed by electron microscopy are clearly gold-rich and the smaller detected by mapping are nickel-rich. Varying the proportions of $\mathrm{Au}$ and $\mathrm{Ni}$, it is possible to modulate the catalytic activity and selectivity. The bimetallic $\mathrm{Au}-\mathrm{Ni} / \mathrm{TiO}_{2}$ catalyst with $\mathrm{Au}: \mathrm{Ni}$ ratio equal to 1:0.08 shows the best compromise between activity provided by $\mathrm{Ni}$ and selectivity to butenes provided by Au for this selective hydrogenation reaction.

\section{Acknowledgements}

We thank DGAPA-UNAM and CONACYT for funding this work within the framework of projects IN105416 and PDNPN1216, respectively. V.O. and C.W.H. acknowledge the financial support granted by the Designing Materials to Revolutionize and Engineer our Future (DMREF) program of the National Science Foundation (CBET-1437219). 


\section{References}

[1] M. Kang, M.W. Song, T.W. Kim, K.L. Kim, Can. J. Chem. Eng. 80 (2002) 63.

[2] M.L. Derrien, Stud. Surf, Sci. Catal. 27 (1986) 613.

[3] S.T. Qi, B.A. Cheney, R.Y. Zheng, W.W. Lonergan, W.T. Yu, J.G.G. Chen, Appl. Catal., A: Gen. 393 (2011) 44.

[4] Y. Zhang, X. Cui, F. Shi, Y. Deng, Chem. Rev. 112 (2012) 2467.

[5] A. Hugon, L. Delannoy, C. Louis, Gold Bull. 41 (2008) 127.

[6] A. Hugon, L. Delannoy, J.-M. Krafft, C. Louis, J. Phys. Chem. C. 114 (2010) 10823.

[7] F. Alonso, P. Riente, M. Yus, Tetrahedron. 64 (2008) 1847.

[8] Y. Okamoto, Y. Nitta, T. Imanaka, S. Teranishi, J. Catal. 64 (1980) 397.

[9] R. Zanella, L. Delannoy, C. Louis, Appl. Catal., A: Gen. 291 (2005) 62.

[10] R. Zanella, C. Louis, Catal. Today. 107-108 (2005) 768.

[11] R. Zanella, S. Giorgio, C.R. Henry, C. Louis, J. Phys. Chem. B. (2002) 7634.

[12] H. Demers, N. Poirier-Demers, A.R. Couture, D. Joly, M. Guilmain, N. De Jonge, D. Drouin, Scanning. 33 (2011) 135.

[13] A. Sandoval, A. Aguilar, C. Louis, A. Traverse, R. Zanella, J. Catal. 281 (2011) 40.

[14] J.J. Phillipson, P.B. Wells, G.R. Wilson, J. Chem. Soc. A. 9 (1969) 1351

[15] L. McEwan, M. Julius, S. Roberts, J. Fletcher, Gold Bull. 43 (2010) 298.

[16] X.F. Yang, A.Q. Wang, Y.L. Wang, T. Zhang, J. Li, J. Phys. Chem. C. 114 (2010) 3131.

[17] V. Idakiev, L. Ilieva, D. Andreeva, J.L. Blin, L. Gigot, B.L. Su, Appl. Catal., A: Gen. 243 (2003) 25.

[18] G. Yuan, C. Louis, L. Delannoy, M. Keane, J. Catal. 247 (2007) 256.

[19] K. Takanabe, K. Nagaoka, K. Nariai, K.-I. Aika, J. Catal. 232 (2005) 268.

[20] A. Sandoval, A. Gómez-Cortés, R. Zanella, G. Díaz, J.M. Saniger, J. Mol. Catal. A Chem. 278 (2007) 200.

[21] J.A. Reyes-Esqueda, A. Bautista-Salvador, R. Zanella, J. Nanosci. Nanotechnol. 8 (2008) 3843.

[22] O.G. Morales-Saavedra, R. Zanella, Mater. Chem. Phys. 124 (2010) 816.

[23] A. Sandoval, C. Louis, R. Zanella, Appl. Catal. B. Environ. 140-141 (2013) 363.

[24] S. Xiao, W. Hu, W. Luo, Y. Wu, X. Li, H. Deng, Eur. Phys. J. B. 54 (2006) 479.

[25] A.A. Herzing, C.J. Kiely, A.F. Carley, P. Landon, G.J. Hutchings, Science 321 (2008) 1331.

[26] V. Ortalan, A. Uzun, B.C. Gates, N.D. Browning, Nat. Nanotech. 5 (2010) 
843.

[27] A. Hugon, L. Delannoy, C. Louis, Gold Bull. 42 (2009) 310.

[28] G. Kyriakou, M.B. Boucher, A.D. Jewell, E.A. Lewis, T.J. Lawton, A.E. Baber, H.L. Tierney, M. Flytzani-Stephanopolous, E.C.H. Sykes, Science 335 (2012) 1209.

[29] H. Yan, H. Cheng, H. Yi, Y. Lin, T. Yao, C. Wang, J. Li, S. Wei, J. Lu, J. Am. Chem. Soc. 137 (2015) 10484

[30] M.A. Ruiz-Preciado, A. Bulou, M. Makowska-Janusik, A. Gibaud, A. Morales-Acevedo, A. Kassiba, CrystEngComm. 18 (2016) 3229.

[31] H. Khojasteh, M. Salavati-Niasari, S. Mortazavi-Derazkola, J. Mater. Sci Mater. Electron. 27 (2016) 3599.

[32] G. Zhou, Y.S. Kang, J. Dispers. Sci. Technol. 27 (2006) 727. 
Table 1 Theoretical and experimental loadings and average metal particle size determined by TEM in the catalysts activated in $\mathrm{H}_{2}$ at $400{ }^{\circ} \mathrm{C}$ in the studied catalysts

\begin{tabular}{|c|c|c|c|c|c|c|c|}
\hline \multirow{2}{*}{ Catalyst } & \multicolumn{4}{|c|}{ Metal loading wt.\% } & \multirow{2}{*}{$\begin{array}{c}\text { Actual } \\
\text { Au:Ni } \\
\text { atomic } \\
\text { ratio }\end{array}$} & \multirow{2}{*}{$\begin{array}{c}\text { Particle } \\
\text { size }(n m)\end{array}$} & \multirow{2}{*}{$\begin{array}{l}\text { Standard } \\
\text { deviation }\end{array}$} \\
\hline & $\begin{array}{c}\text { Nominal } \\
\text { Au loading }\end{array}$ & $\begin{array}{c}\text { Actual } \mathrm{Au} \\
\text { loading }\end{array}$ & $\begin{array}{l}\text { Nominal } \\
\text { Ni loading }\end{array}$ & $\begin{array}{l}\text { Actual } \mathrm{Ni} \\
\text { loading }\end{array}$ & & & \\
\hline $\mathrm{Au}$ & 1 & 1.2 & -- & -- & -- & 2.7 & 0.75 \\
\hline $\mathrm{Ni}$ & -- & -- & 0.28 & 0.24 & -- & 4.2 & 0.67 \\
\hline $\begin{array}{c}\mathrm{Au}-\mathrm{Ni} \\
1: 0.5 \\
\end{array}$ & 1 & 1.2 & 0.14 & 0.2 & $1: 0.6$ & 2.7 & 0.54 \\
\hline $\begin{array}{c}\mathrm{Au}-\mathrm{Ni} \\
1: 0.2 \\
\end{array}$ & 1 & 1.2 & 0.06 & 0.07 & 1:0.2 & 2.6 & 0.67 \\
\hline $\begin{array}{c}\mathrm{Au}-\mathrm{Ni} \\
1: 0.1 \\
\end{array}$ & 1 & 1 & 0.03 & 0.027 & $1: 0.08$ & 2.2 & 0.63 \\
\hline
\end{tabular}

Table 2 Conversion of propene, selectivity to 1-butene, trans-2-butene, 2-cisbutene and total selectivity to butenes of the catalysts, at the temperature corresponding to $100 \%$ butadiene conversion $\left(\mathrm{T}_{100 \%}\right)$ except for $\mathrm{Ni} / \mathrm{TiO}_{2}$

\begin{tabular}{|c|c|c|c|c|c|c|}
\hline Catalyst & $\mathrm{T}_{100 \%}\left({ }^{\circ} \mathrm{C}\right)$ & $\begin{array}{c}\text { Conversion of } \\
\text { propene }(\%)\end{array}$ & $\begin{array}{c}\mathrm{S}_{1-\text { butene }} \\
(\%)\end{array}$ & $\begin{array}{c}\mathrm{S}_{\text {trans-2-butene }} \\
(\%)\end{array}$ & $\begin{array}{c}\mathrm{S}_{\text {cis-2-butene }} \\
(\%)\end{array}$ & $\begin{array}{c}\mathrm{S}_{\text {Tbutenes }} \\
(\%)\end{array}$ \\
\hline $\mathrm{Au}$ & 225 & 0.2 & 59 & 14 & 27 & 100 \\
\hline $\mathrm{Ni}$ & $<30$ & $17^{*}$ & $3^{*}$ & $33^{*}$ & $16^{*}$ & $52^{*}$ \\
\hline $\mathrm{Au}-\mathrm{Ni} 1: 0.6$ & 45 & 1 & 18 & 52 & 23 & 93 \\
\hline $\mathrm{Au}-\mathrm{Ni} \mathrm{1:0.2}$ & 90 & 0.8 & 16 & 58 & 25 & 99 \\
\hline Au-Ni 1:0.08 & 120 & 0.3 & 26 & 50 & 24 & 100 \\
\hline
\end{tabular}

${ }^{*}$ at $30^{\circ} \mathrm{C}$ 
Table 3 Chemical compositions of 31 bimetallic nanoparticles in $\mathrm{Au}-\mathrm{Ni} / \mathrm{TiO}_{2}$ 1:0.6 (i.e., 62.5:37.5 Au:Ni, at\%) evaluated by STEM-EDX as a function of their size

\begin{tabular}{|c|c|c|c|c|}
\hline $\begin{array}{c}\text { Size range } \\
(\mathrm{nm})\end{array}$ & $\begin{array}{c}\text { Number of } \\
\text { particles }\end{array}$ & $\begin{array}{c}\text { Average particle } \\
\text { size }(\mathrm{nm})\end{array}$ & $\begin{array}{c}\text { Number of } \\
\text { monometallic gold } \\
\text { particles }\end{array}$ & $\begin{array}{c}\text { Average } \\
\text { composition } \\
\text { (Au:Ni, at\%) }\end{array}$ \\
\hline $0-1.9$ & 13 & 1.4 & 1 & $\begin{array}{c}82.6 \pm 11.6: \\
17: 4 \pm 11.6\end{array}$ \\
\hline $2-3.9$ & 6 & 2.8 & 2 & $\begin{array}{c}96.6 \pm 0.88: \\
3.4 \pm 0.88\end{array}$ \\
\hline $4-5.9$ & 8 & 5.1 & 5 & $\begin{array}{c}99.2 \pm 0.54: \\
0.8 \pm 0.54\end{array}$ \\
\hline $6-7.9$ & 4 & 7.0 & 1 & $98.7 \pm 0.54:$ \\
& & & & $1.3 \pm 0.54$ \\
\hline
\end{tabular}



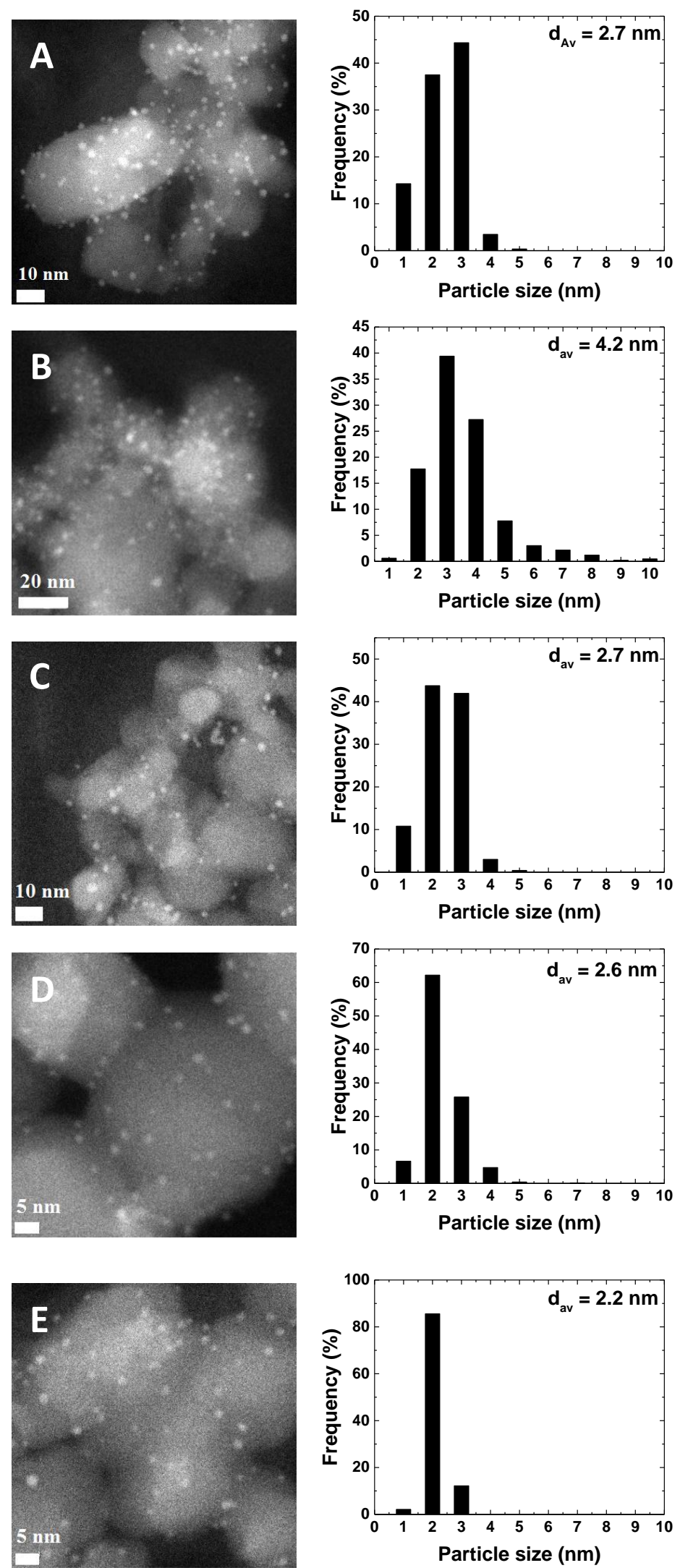

Figure 1 TEM-HAADF images and histograms of particle sizes of monometallic (A) $\mathrm{Au} / \mathrm{TiO}_{2}$, (B) $\mathrm{Ni} / \mathrm{TiO}_{2}$ and bimetallic Au-Ni/TiO $(\mathrm{C})$ 1:0.6 (D) 1:0.2 y (E) 1:0.08 samples reduced at $400{ }^{\circ} \mathrm{C}$ in $\mathrm{H}_{2}$ 

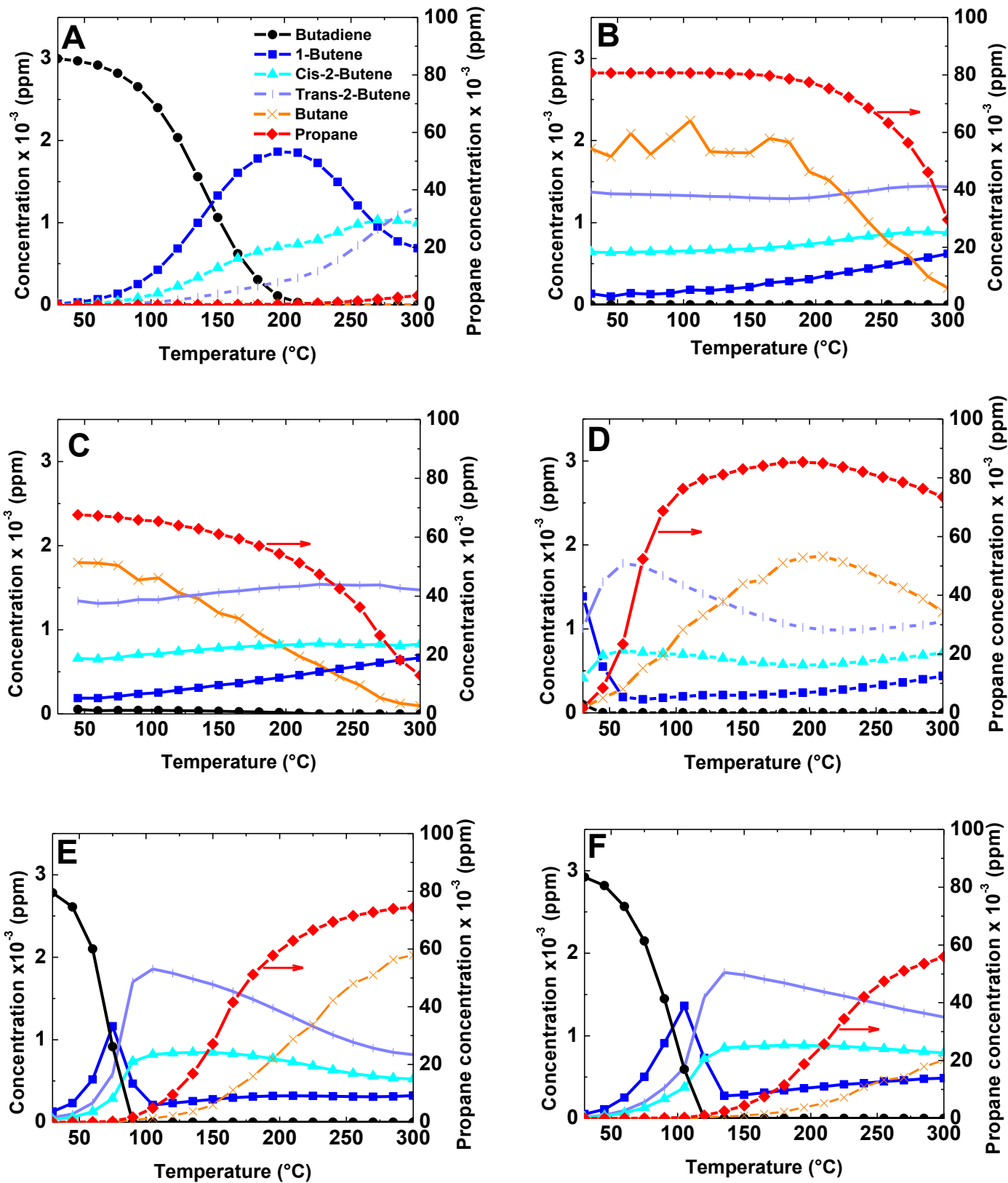

Figure 2 Evolution of the concentrations of the reactants and products as a function of the reaction temperature over (A) $\mathrm{Au} / \mathrm{TiO}_{2},(B) \mathrm{Ni} / \mathrm{TiO}_{2}$, (C) Mechanical mixture, and bimetallic Au-Ni/ $\mathrm{TiO}_{2}$ (D) 1:0.6, (E) 1:0.2 and (F) 1:0.08 catalysts activated at $400{ }^{\circ} \mathrm{C}$ in $\mathrm{H}_{2}$ 


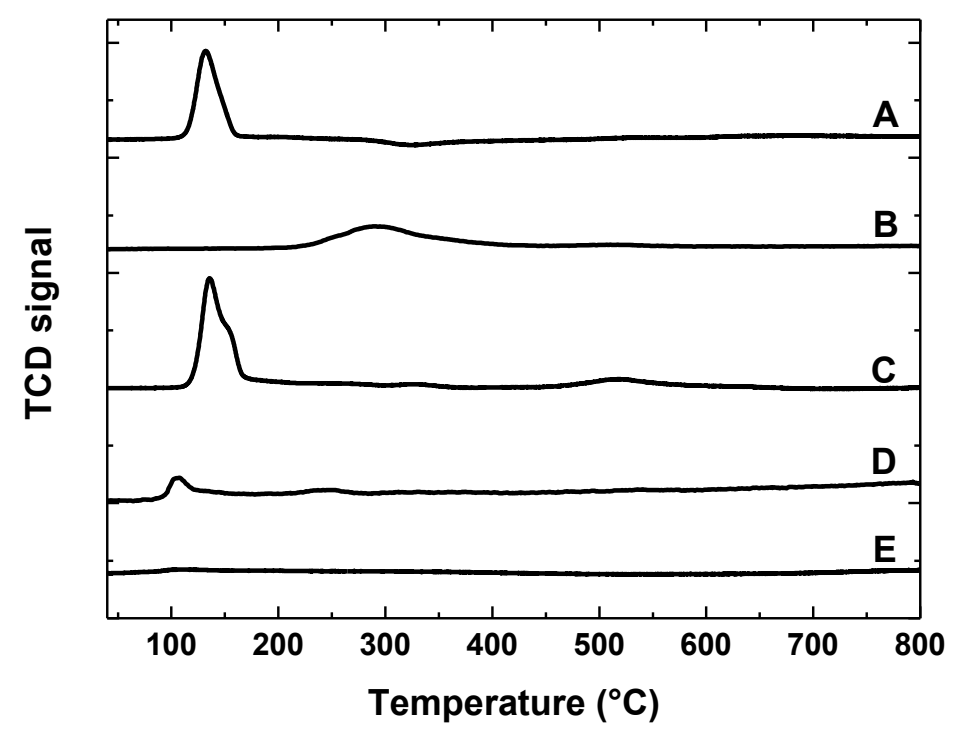

Figure 3 TPR profiles of as-prepared (A) Au/ $/ \mathrm{TiO}_{2}$, (B) Ni/TiO ${ }_{2}$, (C) Au-Ni/TiO $1: 0.6$, and (D) $\mathrm{Ni} / \mathrm{TiO}_{2}$ and $(\mathrm{E}) \mathrm{Au}-\mathrm{Ni} / \mathrm{TiO}_{2}$ 1:0.6 exposed to air for one week after first TPR test 

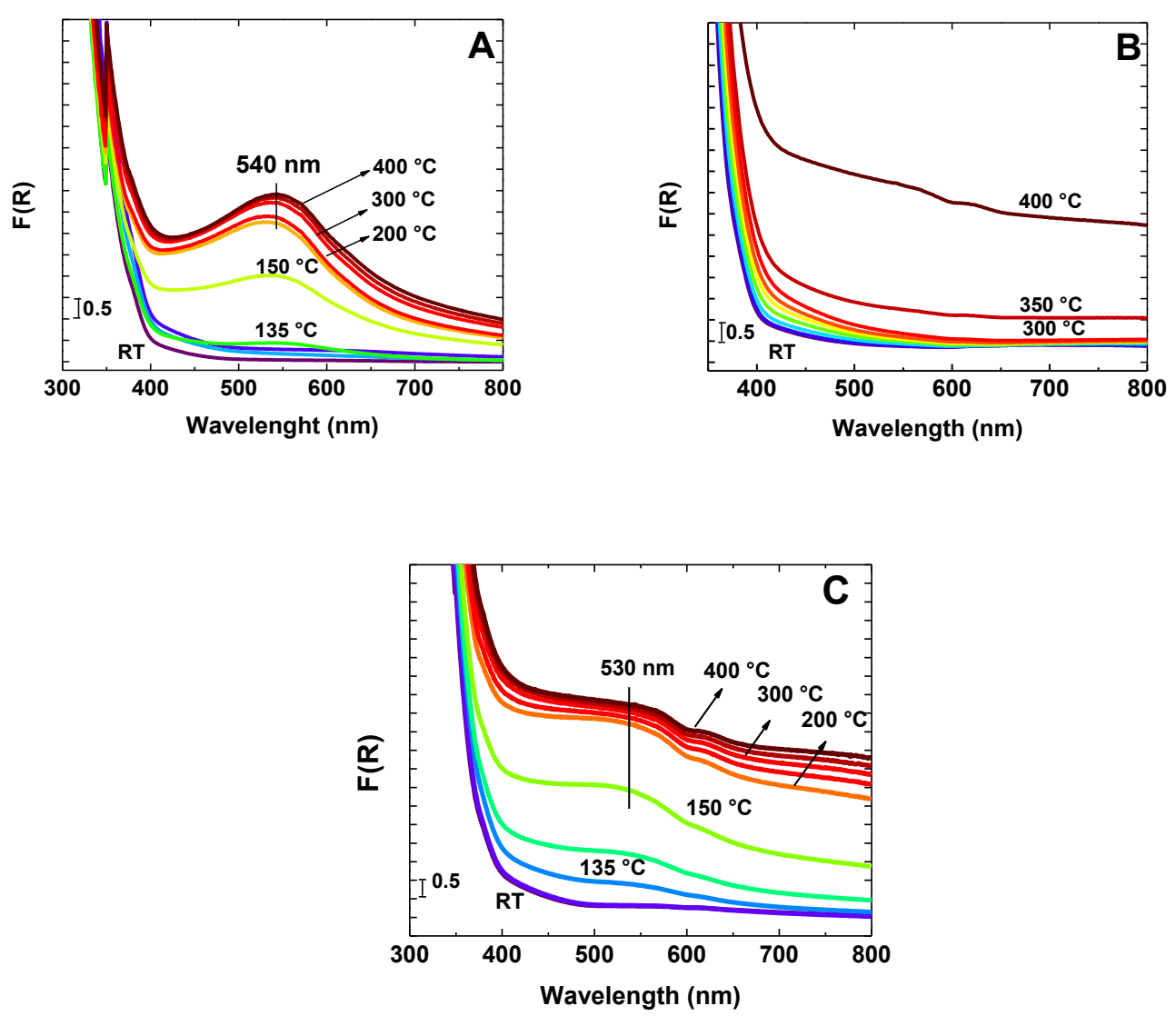

Figure 4 UV-Visible spectra of samples reduced in situ under hydrogen at increasing temperatures for as-prepared (A) $\mathrm{Au} / \mathrm{TiO}_{2},(\mathrm{~B}) \mathrm{Ni} / \mathrm{TiO}_{2}$ and (C) Au$\mathrm{Ni} / \mathrm{TiO}_{2}$ 1:0.6 samples 


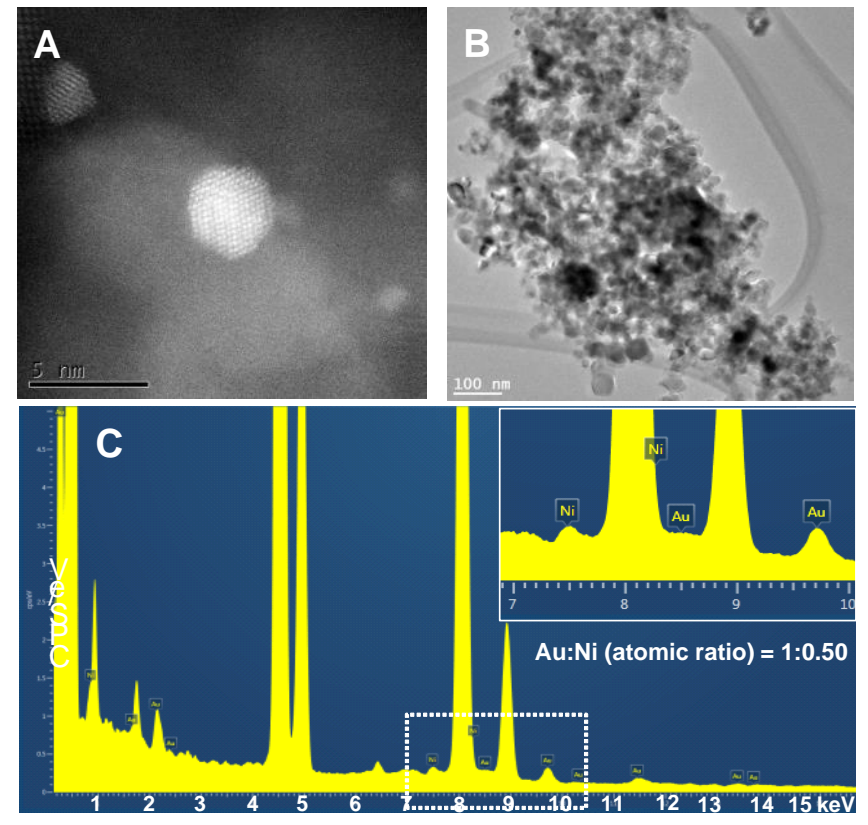

Figure $5(A)$ aberration corrected HAADF-STEM image of a bimetallic particle in $\mathrm{Au}-\mathrm{Ni} / \mathrm{TiO}_{2}$ 1:0.6; (B) TEM image of a large area of $\mathrm{Au}-\mathrm{Ni} / \mathrm{TiO}_{2} 1: 0.6$ and (C) the corresponding XEDS spectra collected from the entire sample shown in B 

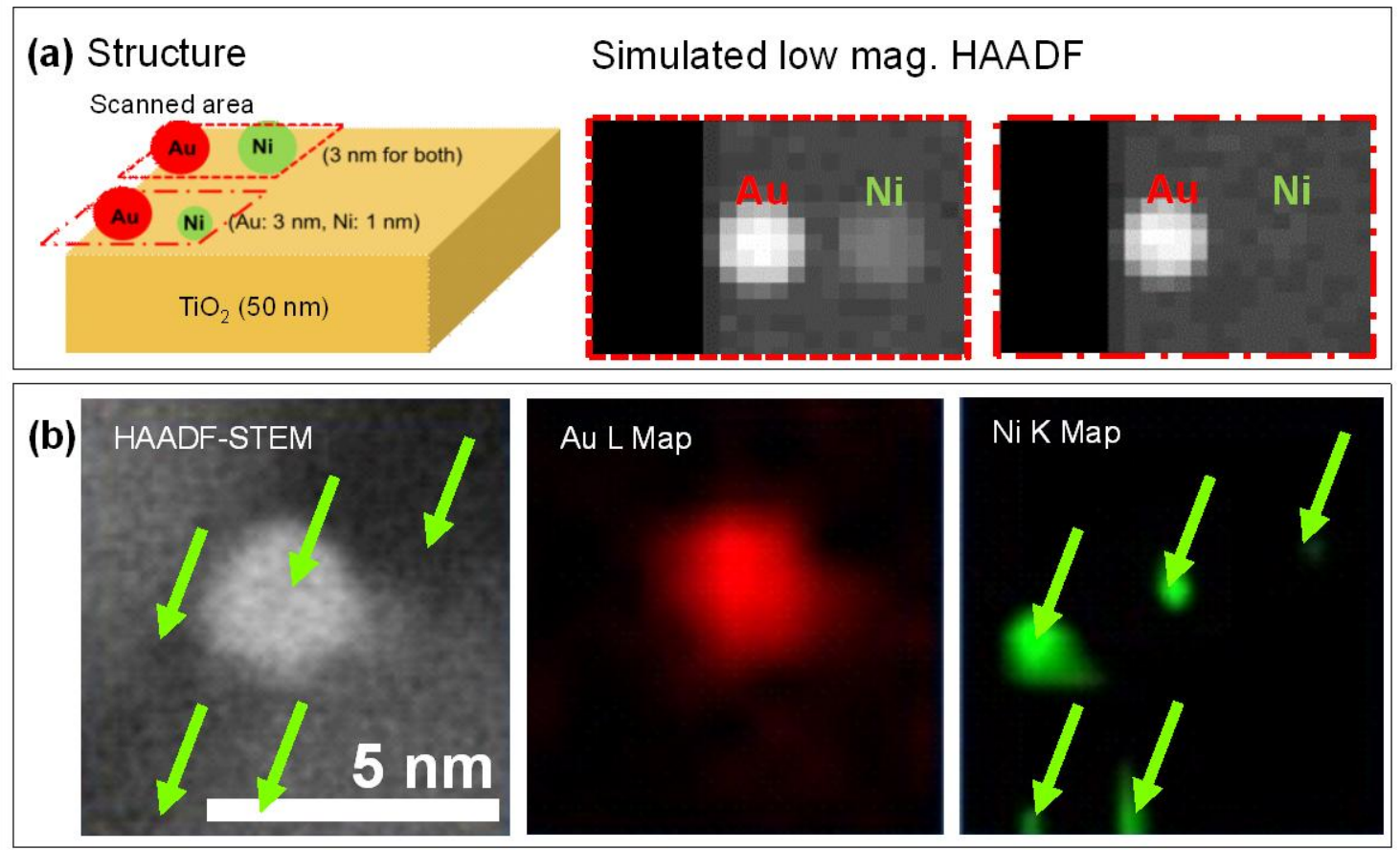

Figure 6 Simulated and experimental HAADF image of $\mathrm{Au}-\mathrm{Ni} / \mathrm{TiO}_{2}$ 1:1. (A) Simulated structure and corresponding low mag. HAADF image (right) (B) HAADF-STEM image (left), XEDS Au-L map (middle), and Ni-K map (right) 

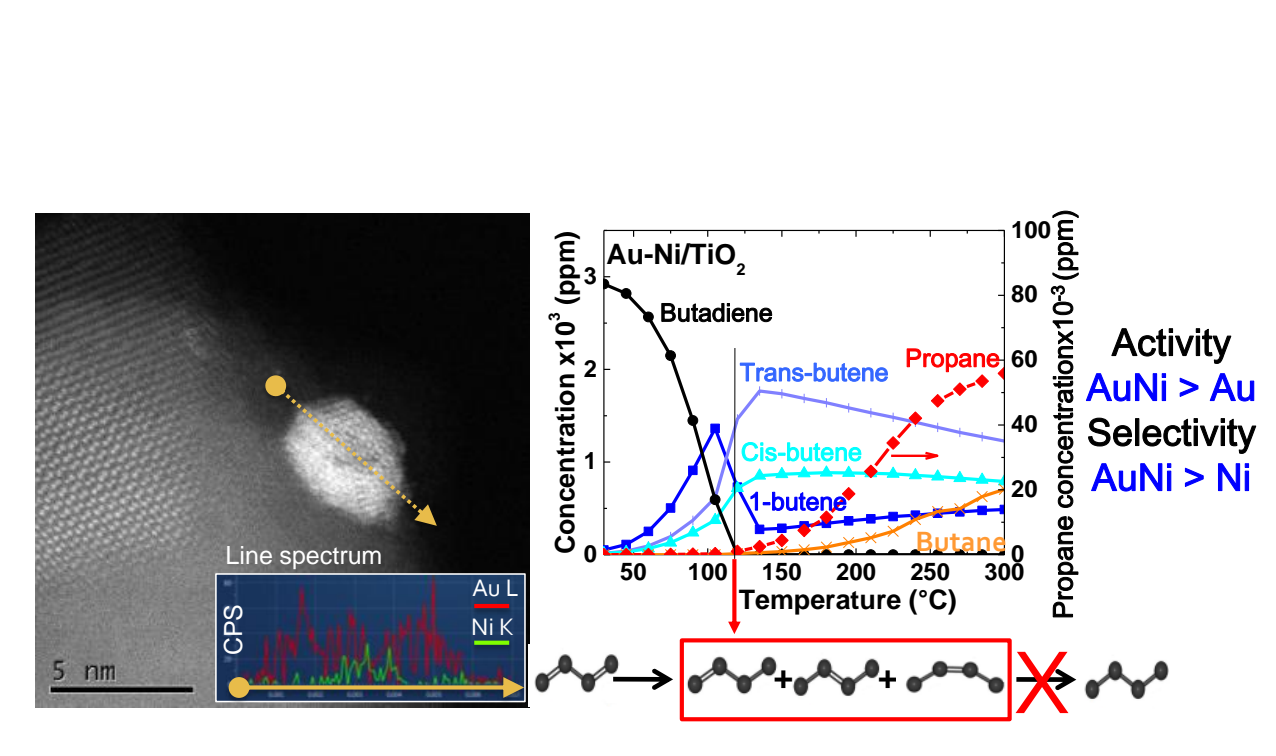

\section{Graphical Abstract}

